\title{
CORRECTION
}

View Article Online

View Journal I View Issue

\section{Correction: Inhomogeneities and local chain stretching in partially swollen networks}

Cite this: Soft Matter, 2015, 11, 4337

\author{
Walter Chassé, ${ }^{* a}$ Sandra Schlögl, ${ }^{b}$ Gisbert Riess ${ }^{c}$ and Kay Saalwächter ${ }^{\star^{a}}$
}

Correction for 'Inhomogeneities and local chain stretching in partially swollen networks' by Walter

DOI: $10.1039 / c 5 s m 90081 f$

Chassé et al., Soft Matter, 2013, 9, 6943-6954.

www.rsc.org/softmatter

Eqn (3) in the original manuscript needs to be replaced by

$$
M_{\mathrm{c}, \mathrm{app}}=M_{\mathrm{c}} \frac{f}{f-2}=-\frac{\rho_{\mathrm{p}} V_{\mathrm{s}} \omega_{\mathrm{el}} \phi_{\mathrm{p}}^{* \frac{1}{3}}}{\ln \left(1-\phi_{\mathrm{p}}^{*}\right)+\phi_{\mathrm{p}}^{*}+\chi \phi_{\mathrm{p}}^{* 2}}
$$

The previous version of the above Flory-Rehner equation incorporated an earlier suggested ${ }^{1}$ and later revised ${ }^{2}$ incorrect account of a fraction of elastically inactive defects $\omega_{\mathrm{def}, \mathrm{sw}}$, as determined by NMR experiments in the swollen state. In short, the previous version incorporated a modified $\phi_{\mathrm{p}, \mathrm{el}}^{*}{ }^{\frac{1}{3}}=\left[\left(1-\omega_{\mathrm{def}, \mathrm{sw}}\right) \phi_{\mathrm{p}}^{*}\right]^{\frac{1}{3}}$ dependence on the polymer volume fraction at swelling equilibrium in the numerator. The dependence on $\phi_{\mathrm{p}}^{*}$, however, merely relates to the geometric deformation of the sample as a whole, not to the fact that a part of the material is inactive. Rather, the fraction of elastically active material $\omega_{\mathrm{el}}=1-\omega_{\mathrm{def}, \mathrm{sw}}$ is to be used to correct the resulting overall density of active network chains $1 / M_{c}$, resulting in eqn (1).

Our revision $^{2}$ has also revealed that the interaction parameter $\chi$ for PDMS/toluene, to be used in the above equation, should be revised in so far as a different literature value, ${ }^{3} \chi=0.445+0.287 \phi_{\mathrm{p}}^{*}$, provided more conclusive results. The corrections only affect the results shown in the final Fig. 9 of the paper, see Fig. 1 for a revised version. The overall changes are minor, amounting to systematic shifts of the absolute-value results for $1 / M_{\mathrm{c}, \text { app }}$, but not to significant changes in the relative linear relationships. Thus, all drawn conclusions remain valid.

\footnotetext{
${ }^{a}$ Institut für Physik - NMR, Martin-Luther-Universität Halle-Wittenberg, Betty-Heimann-Str. 7, D-06120 Halle, Germany. E-mail: walter.chasse@physik.uni-halle.de

${ }^{b}$ Polymer Competence Center Leoben GmbH, Roseggerstrasse 12, Leoben 8700, Austria

${ }^{c}$ Institute of Chemistry of Polymeric Materials, University of Leoben, Otto Glöckel-Strasse 2, Leoben 8700, Austria
} 

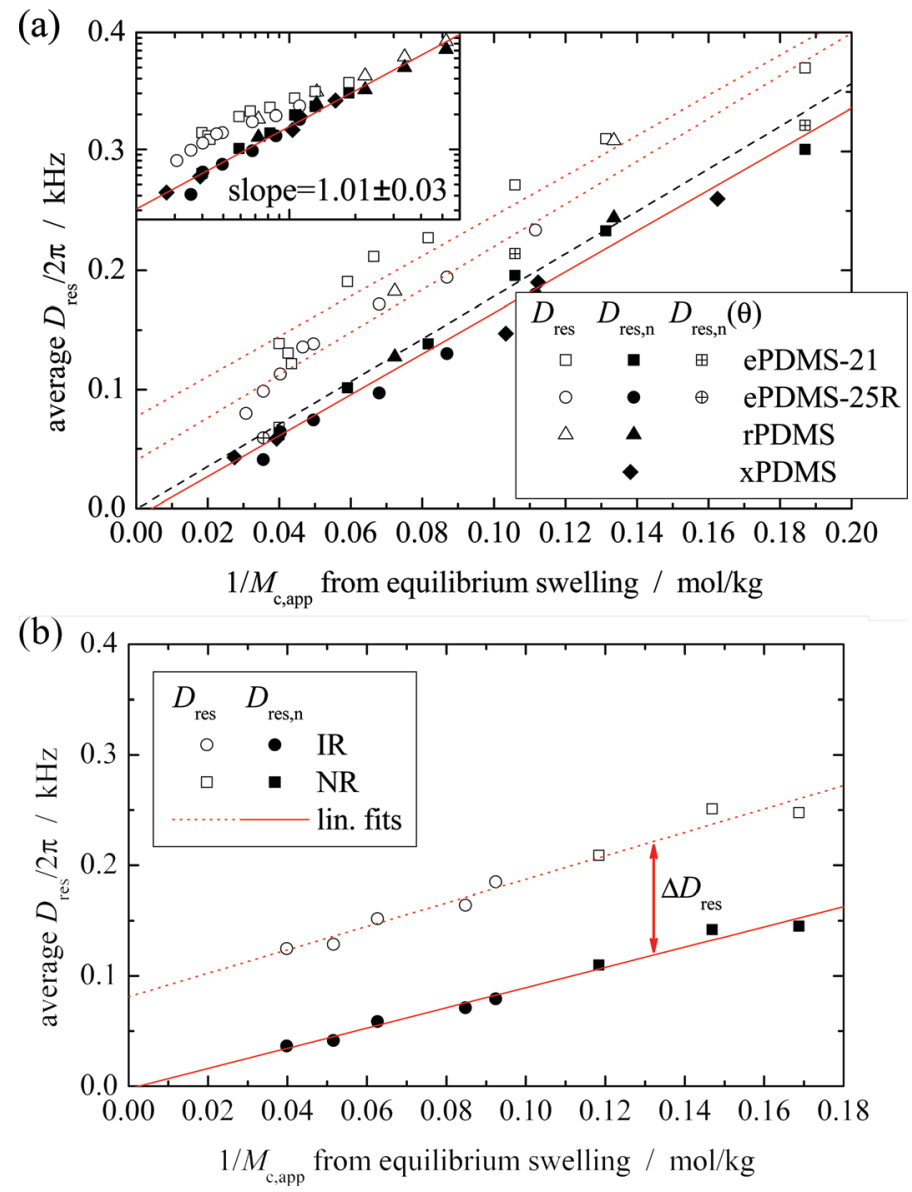

Fig. 1 Corrected version of Fig. 9 of original manuscript.

\section{References}

1 W. Chassé, M. Lang, J.-U. Sommer and K. Saalwächter, Macromolecules, 2012, 45, 899-912.

2 W. Chassé, M. Lang, J.-U. Sommer and K. Saalwächter, Macromolecules, 2015, 48, 1267-1268.

3 N. Kuwahara, T. Okazawa and M. Kaneko, J. Polym. Sci., Part C: Polym. Symp., 1968, 23, 543-553.

The Royal Society of Chemistry apologises for these errors and any consequent inconvenience to authors and readers. 